\title{
Motor cognitive processing speed estimation among the primary schoolchildren by deriving prediction formula: A cross-sectional study
}

\author{
Vencita Priyanka Aranha, Monika Moitra ${ }^{1}$, Shikha Saxena ${ }^{2}$, Kanimozhi Narkeesh ${ }^{1}$, Narkeesh Arumugam³, \\ Asir John Samuel \\ Departments of Pediatric Physiotherapy and ${ }^{1}$ Musculoskeletal Physiotherapy, Maharishi Markandeshwar Institute of Physiotherapy and \\ Rehabilitation, Mullana, Haryana, ${ }^{2}$ Department of Graduate Studies, School of Physical and Occupational Therapy, McGill University, Montreal, \\ Quebec, Canada, ${ }^{3}$ Department of Physiotherapy, Punjabi University, Patiala, Punjab, India
}

\begin{abstract}
Objectives: Motor cognitive processing speed (MCPS) is often reported in terms of reaction time. In spite of being a significant indicator of function, behavior, and performance, MCPS is rarely used in clinics and schools to identify kids with slowed motor cognitive processing. The reason behind this is the lack of availability of convenient formula to estimate MCPS. Thereby, the aim of this study is to estimate the MCPS in the primary schoolchildren. Materials and Methods: Two hundred and four primary schoolchildren, aged 6-12 years, were recruited by the cluster sampling method for this cross-sectional study. MCPS was estimated by the ruler drop method (RDM). By this method, a metallic stainless steel ruler was suspended vertically such that $5 \mathrm{~cm}$ graduation of the lower was aligned between the web space of the child's hand, and the child was asked to catch the moving ruler as quickly as possible, once released from the examiner's hand. Distance the ruler traveled was recorded and converted into time, which is the MCPS. Multiple regression analysis of variables was performed to determine the influence of independent variables on MCPS. Results: Mean MCPS of the entire sample of 204 primary schoolchildren is $230.01 \mathrm{~ms} \pm 26.5$ standard deviation ( $95 \%$ confidence interval; 226.4-233.7 ms) that ranged from 162.9 to $321.6 \mathrm{~ms}$. By stepwise regression analysis, we derived the regression equation, MCPS $(\mathrm{ms})=279.625-5.495 \times$ age, with $41.3 \%(R=0.413)$ predictability and $17.1 \%\left(R^{2}=0.171\right.$ and adjusted $\left.R^{2}=0.166\right)$ variability. Conclusion: MCPS prediction formula through RDM in the primary schoolchildren has been established.
\end{abstract}

Key words: Children, cognitive psychology, prediction equation, reaction time, response time

\section{Introduction}

Time lapse between the application of stimulus and generation of appropriate voluntary response in an individual is known as reaction time (RT). ${ }^{[1]}$ It has been used widely in the assessment of executive functions, neuropsychological functions, and motor

\section{Address for correspondence:}

Dr. Asir John Samuel, Maharishi Markandeshwar Institute of Physiotherapy and Rehabilitation, Maharishi Markandeshwar University, Mullana - 133 207, Haryana, India.

E-mail: asir.j.samuel@gmail.com

\begin{tabular}{|l|l|}
\hline \multicolumn{2}{|c|}{ Access this article online } \\
\hline Quick Response Code: & Website: \\
\hline & www.ruralneuropractice.com \\
\cline { 2 - 2 } & \\
\hline
\end{tabular}

cognitive processing speed (MCPS). ${ }^{[2-4]}$ MCPS varies with number of possible valid stimulus, type, order and intensity of stimulus, arousal, age, gender, physical fitness, hand dominance, practice and error, fatigue, fasting, distraction, alcohol, finger tremor, stress, drugs, intelligence, learning disorder, brain injury, illness, personality type, and accuracy in hearing and vision. ${ }^{[1,5]}$ Lesser MCPS accelerates the achievements in various fields such as games, studies, fine arts, martial arts, and defense. By identifying the person's MCPS, we can predict the reacting abilities in the above-mentioned

This is an open access article distributed under the terms of the Creative Commons Attribution-NonCommercial-ShareAlike 3.0 License, which allows others to remix, tweak, and build upon the work non-commercially, as long as the author is credited and the new creations are licensed under the identical terms.

For reprints contact: reprints@medknow.com

How to cite this article: Aranha VP, Moitra M, Saxena S, Narkeesh K, Arumugam N, Samuel AJ. Motor cognitive processing speed estimation among the primary schoolchildren by deriving prediction formula: $A$ cross-sectional study. J Neurosci Rural Pract 2017;8:79-83. 
situations. In case of children, this guides us to diagnose the children with sustained RT and its origin. Personal consideration can be given to them at their budding years of life. Thus, estimating MCPS of children at small age is more relevant.

MCPS of an individual is estimated clinically by computerized neuropsychological test. ${ }^{[6]}$ However, high cost and professional guidance in estimating RT make this unavailable for the schoolchildren. Although mobile-based android applications are available for estimating RT, the restricted usage of mobiles at schools makes this as a tough task. Hence, there is a need to validate a simple gadget frequently used in schools such as ruler. Ruler drop method (RDM) is another simplest method to estimate the MCPS. The participant/athlete was asked to perform RDM by sitting on a chair of appropriate height with his/ her dominant forearm resting on a flat horizontal table surface. The hand was kept open at the edge of the table. The ruler was dangled erect by an examiner/assistant such that the other end of the ruler was aligned with the top of the participant/athlete open hand and he/she was instructed to catch the ruler quickly once it was dropped by the examiner/assistant. Then, the distance traveled by the ruler was converted into time by the formula, $d=v t+1 / 2 a t^{2} .{ }^{[7]}$

Eckner et al. validated this simple instrument for the estimation of MCPS. ${ }^{[8]}$ However, the instrument has ceiling effect, and in case of children, it might have a major effect. To minimize this effect, we have proposed a simple method to estimate MCPS by a ruler dropped at least a meter distance from the ground. A stainless steel meter ruler is used in the study to estimate the RT in children. ${ }^{[9]}$ In our pilot study, we evaluated the reliability and validity of RT of 12 schoolchildren aged between 6 and 10 years using RDM. We used a metal ruler with $1 \mathrm{~m}$ length. We performed a small modification in the procedure that the ruler was suspended vertically such that $5 \mathrm{~cm}$ below the child's open hand, and the distance the ruler traveled from the initial point was recorded. The trial was repeated for 3 times. To estimate the validity of RDM, we used an android-based mobile application known as criterion-referenced Reaction Speed $^{\circledR}$. We found good intrarater reliability $(0.81)$ and moderate-to-good degree of validity (0.54). ${ }^{[9]}$ This study was aimed to derive a prediction equation to estimate MCPS among the primary schoolchildren by RDM.

\section{Materials and Methods}

\section{Recruitment of children}

A total of 204 children participated in this cross-sectional study with prior permission from the principal of participating school and also from the parents/legal guardians by cluster sampling technique. The ethical clearance was obtained from the University Research Ethics Committee of Maharishi Markandeshwar University, Mullana, Ambala, Haryana, India (MMU/ IEC/445). The study was performed according to ground rules settled by the Declaration of Helsinki (Revised 2013). The assent from children and written consent from their parents/legal guardians were collected prior to the study. Children with confirmed history of neurological, orthopedic, and metabolic disorders, upper extremity injury or surgery, complaints of weakness or pain, and any other mediwcal, surgical, and psychological conditions were excluded from the study.

\section{Measuring motor cognitive processing speed}

All anthropometric measurements were taken before the beginning of the study in a sports laboratory. Body weight was measured in children with minimum clothing by a calibrated weighing scale (Equinox BR-9015, Analog Weighing Scale), and height was measured in centimeters, without shoes and socks, with a standard height measuring flat metallic piece over a mounting measuring tape (Freemans ${ }^{\circledast}$ MRL $2 \mathrm{~m} 16 \mathrm{~mm}$, Metal Wired Tape) on the wall with feet about $25-30 \mathrm{~cm}$ apart and they were recorded to the nearest $1 \mathrm{~kg}$ and $1 \mathrm{~mm}$, respectively. Body mass index (BMI) was calculated by dividing the weight $(\mathrm{kg})$ by the square of the height $(\mathrm{m})$. To measure MCPS by RDM, the children were asked to sit with their dominant side elbow flexed at $90^{\circ}$ with mid-pronated, and the forearm rested over a flat of the table surface such that the hand was placed outside the table. Ruler was hung down vertically by the investigator such that its lower edge was aligned across $5 \mathrm{~cm}$ between the web space (i.e., thumb and index finger) of the children's hand. Children were instructed to grasp the ruler quickly as it was liberated by examiner as shown in Figure 1.

The vertical distance covered by the ruler from $5 \mathrm{~cm}$ was listed. Then, this distance was converted into MCPS using the following formula, MCPS $=\sqrt{ } 2 d / g$, where $d$ is the distance traveled by the ruler and $g$ is the acceleration due to gravity, a constant $\left(9.8 \mathrm{~m} / \mathrm{s}^{2}\right)$. Three trials were taken, and then, mean of this was used for the analysis of normative value.

\section{Data analysis}

Statistical analysis of the collected data was performed using the Statistical Package for Social Sciences (SPSS, version 20.0 Inc., Chicago, IL, USA) software for Windows 7 Ultimate edition. Normal Gaussian distribution of the 

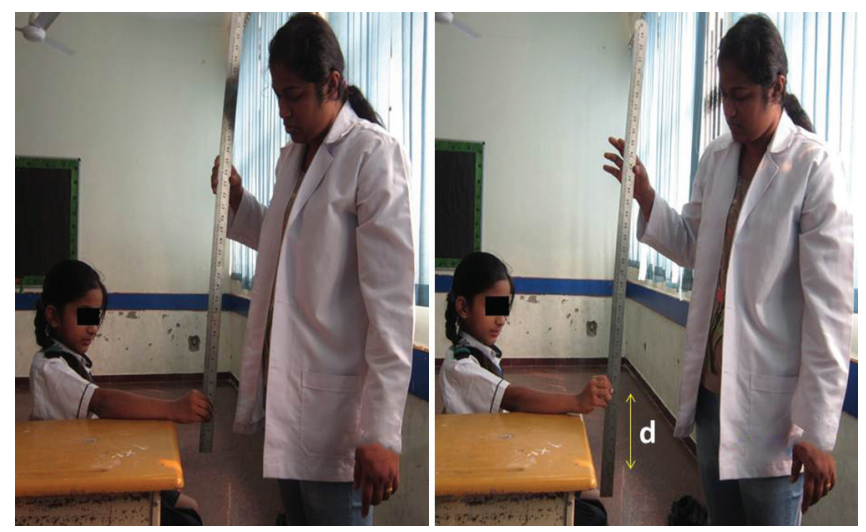

Figure 1: Measuring motor cognitive processing speed by the ruler drop method

Note: Figure 1 has appeared in our previous publication in, Aranha VP, Joshi R, Samuel AJ, Sharma K. Catch the moving ruler and estimate reaction time in children. Indian J Med Health Sci 2015;2:23-6. doi:10.21088/ijmhs.2347.9981.2115.4.

data was verified by the Kolmogorov-Smirnov test. As the data follow normal distribution, descriptive statistics were expressed in terms of mean \pm standard deviation (SD) and 95\% confidential interval (95\% CI). Demographic character differences between male and female were explored by the statistical test of significance, independent $t$-test. Mean RT was reported in mean \pm SD and $95 \% \mathrm{CI}$ with range. To identify the effect of independent variables such as gender, age, height, weight, and BMI over the depending variable, multiple linear regression was used. Multiple linear regression analysis was performed to identify the role of the independent variable such as age, height, weight, and BMI for estimating the RT. By stepwise exclusion, prediction equation for RT in the age group between 6 and 12 years was made.

\section{Results}

A total of 269 children with a mean age of $9.1 \pm 1.9$ years (range of $6-12$ years) were selected for the study. Of these 269 children, 204 passed anthropometric evaluation. Although the recruited sample composed of unequal gender distribution with $56.9 \%$ of female (116) and $43.1 \%$ of male (88), there exist no statistical differences among their demographic parameters $(P>0.05)$, which is shown in Table 1 . Mean MCPS of the entire sample, i.e. $230.01 \mathrm{~ms} \pm 26.5 \mathrm{SD}(95 \%$ CI: $226.4-233.7 \mathrm{~ms}$ ) ranged from 162.9 to $321.6 \mathrm{~ms}$. Standard reference norms of MCPS according to age were shown in Figure 2. The readings suggested that MCPS decreases as age increases. The effect of multiple independent variables which include age, gender, height, weight, and BMI over the dependent variable MCPS was derived from the multiple regression. The overall

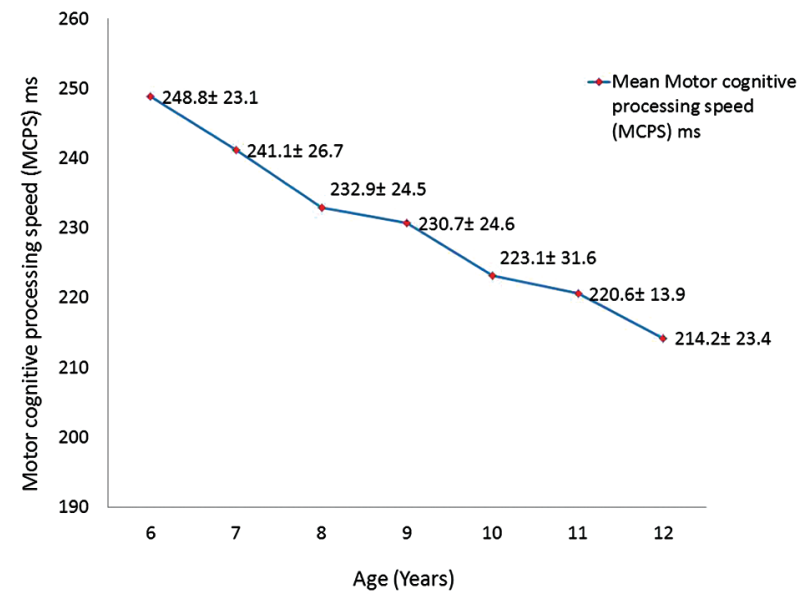

Figure 2: Motor cognitive processing speed (ms) among individual age group expressed in mean (standard deviation)

Table 1: Demographic characteristics of the primary schoolchildren recruited

\begin{tabular}{lccc}
\hline Parameter & \multicolumn{2}{c}{ Mean \pm SD } & $P$ \\
\cline { 2 - 3 } & Male & Female & \\
\hline$n$ & 88 & 116 & \\
Age (years) & $8.6 \pm 2.1$ & $9.3 \pm 1.9$ & 0.12 \\
Height $(\mathrm{cm})$ & $123 \pm 15.2$ & $126.4 \pm 17.7$ & 0.24 \\
Weight $(\mathrm{kg})$ & $22.6 \pm 9.1$ & $24 \pm 8.9$ & 0.27 \\
Body mass index $\left(\mathrm{kg} / \mathrm{m}^{2}\right)$ & $14.8 \pm 5$ & $14.9 \pm 3.8$ & 0.82 \\
\hline
\end{tabular}

SD: Standard deviation

prediction of MCPS by the above independent variables is $R=0.43$ with the variability of $R^{2}=0.19$ and adjusted $R^{2}=0.17$. The $F$-ratio in the ANOVA test demonstrates that the overall regression model is a good fit for the data. Here, the independent variables statistically significantly predict the dependent variable, $F(5,198)=9.078, P<0.001$. Hence, the regression model is a good fit of the data. By stepwise regression analysis, the nonstatistically significant independent variables were excluded from the analysis, and regression analysis was performed by including the independent variable, age of the children, which is only statistically significant $(P<0.001)$.

The predictability of MCPS by age is $41.3 \%(R=0.413)$ with a variability of $17.1 \%\left(R^{2}=0.171\right.$ and adjusted $\left.R^{2}=0.166\right)$ as shown in Table 2 . The derived regression equation is as follows:

MCPS $(\mathrm{ms})=279.625-(5.495 \times$ age $[$ in years] $)$. For example, while estimating MCPS of 8 years, 6 -month-old child, substitute 8.5 for age in the above formula.

\section{Discussion}

The preliminary aim of this study was to establish the prediction equation for MCPS by RDM among primary 
Table 2: Regression analysis of variables to determine the influence of independent variable, age on motor cognitive processing speed

\begin{tabular}{lccccc}
\hline $\begin{array}{l}\text { Independent } \\
\text { variables }\end{array}$ & \multicolumn{2}{c}{$\begin{array}{c}\text { Unstandardized } \\
\text { coefficients }\end{array}$} & $\begin{array}{c}\text { Standardized } \\
\text { coefficients }\end{array}$ & $\boldsymbol{t}$ & Significant \\
\cline { 2 - 3 } & $\mathbf{B}$ & SE & $\boldsymbol{\beta}$ & & \\
\hline Constant & 279.625 & 7.882 & & 35.477 & 0.000 \\
Age & -5.495 & 0.853 & -0.413 & -6.445 & 0.000 \\
\hline
\end{tabular}

Dependent variable: MCPS (ms). MCPS: Motor cognitive processing speed, SE: Standard error

schoolchildren aged between 6 and 12 years. These years, also known as mid-childhood, where they make a move toward adulthood, demonstrate the major shift in their cognitive abilities. ${ }^{[10]}$ As we know RT is the time lapse between the application of stimulus and task completion, the MCPS of an individual can be quantified by calculating RT. RDM is simple and has good inter-rater reliability and it is a good-moderate validity method to assess the simple RT in school-going children. ${ }^{[9,11]}$

The apparatus used here is a universal ruler made by steel with $1 \mathrm{~m}$ length, which is easily available in commercial market in a feasible cost. The length $1 \mathrm{~m}$ is specifically to reduce the ceiling effect. The comprised battery methods which are used to assess RT will not have this upper limit. ${ }^{[8]}$

Newton's second law of motion states that the applied force and weight of moving object determine its acceleration $(a=f / m) \cdot{ }^{[12]}$ However, for an object falling from the height, its own body weight will act as the force $(f=w)$ at constant air resistance. ${ }^{[12]}$ The weight of object is the product of mass and gravity $(w=m \times g) \cdot{ }^{[12]}$ Thus, gravitational force is proportional to its mass and decides the acceleration $(a=m g / m) \cdot{ }^{[12]}$ Thereby, Newton proves the assumptions of Galileo given approximately four century before $(a=g){ }^{[12]}$ Galileo dropped two cannon balls of same size (made up of different material such as wood and iron, respectively) from the top of Pisa tower, and he observed that both balls reach earth at the same time. He reported that the distance covered by the object depends on the square of the time and velocity increased as the ball moves down, ${ }^{[13,14]}$ which suggests that the mass and dimension of the object do not affect the acceleration of the object. ${ }^{[12]}$ Thus, it is clear that the size, shape, and material of the ruler will not alter the result.

From a total of 269 children, we recruited 223 children depending on the selection criteria. Among them, 15 children were absent to the school on the day of data collection. Thus, we collected the data of only 204 children for calculation. Although there exists an unequal gender distribution (boys 88 and girls 116), they are matched in their age $(P=0.12)$, height $(P=0.24)$, weight $(P=0.27)$, and BMI $(0.82)$.

Practice trials were performed before the actual trial, and these trial data were excluded from the analysis. Here, we demonstrated MCPS of 204 children is $230.01 \mathrm{~ms}$, and it varies from 162.9 to $321.6 \mathrm{~ms}$. The considerable variations that are found in the distribution of MCPS is possibly due to person's individuality, complexity of task, and items in the given task. ${ }^{[15]}$ Age group of 10-14 years demonstrates $220 \mathrm{~ms}$ of MCPS by the same method. ${ }^{[16]}$ The MCPS for children between 8 and 10 years measured by anxiety related informationprocessing biases method lies close to our findings. ${ }^{[17]}$ The highly trained children can exhibit significantly shorter RT than other children of similar age group. Fong et al. proved this by comparing the MCPS of international level qualified taekwondo (a form of martial art) players $(0.19 \pm 0.03 \mathrm{~s})$ of $10-16$ years with the nontrained children $(0.22 \pm 0.02 \mathrm{~s})$ of the same age. ${ }^{[16]}$ Another study of comparing MCPS between circus artist and nontrained adults of the same age group shows significant differences in their MCPS. ${ }^{[18]}$

The RT or MCPS is typically related to age but it varies. ${ }^{[19]}$ Our study report also exhibits these age-related differences in mean MCPS among different age. ${ }^{[20]}$ The RT and age are inversely related to each other. Approximately up to an age of 50 years, the mean MCPS will decrease with progression of age. ${ }^{[19]}$ Then, it starts to incline gradually with respect to increasing age. This reduction in MCPS with increasing age may be due to distracted attention, ignorance, declining cognitive ability, and motor response. ${ }^{[21,22]}$ The development of human brain according to heterochronicity principle may be another possible reason for the age-related MCPS differences. ${ }^{[23]}$ This is also supported by the regression analysis in identifying the factors affecting MCPS. By considering the prediction equation, MCPS $(\mathrm{ms})=279.625-(5.495 \times$ age $)$, RT can be estimated in the children aged between 6 and 12 years. The MCPS difference among individual age group between 6 and 12 years is relatively constant; it is also supported by Rueda's study on the development of attention network among 6-10-year-old children. ${ }^{[24]}$

In our experience during testing and data collection, the RDM was easy to perform and individual child responded with nearly homogeneous eagerness and competitiveness. The children found that dropping ruler is intrinsically interesting, and hence, they appeared to be motivated to give excellent outcome. This study has few limitations too. First is the inevitable human error in recording the distance traveled by the ruler. Second, other variables which could affect MCPS such as intelligent 
quotient, sociodemographics, and child behavior were not assessed. Third, not analyzing the muscle and nerve parameter such as muscle cross-section area, muscle strength, pinch grip, and nerve conduction velocity, which is beyond the scope of this study. Nevertheless, this is the first study to derive the prediction equation for MCPS among the primary schoolchildren by the simple method, RDM. Further, the study can be extended over the other age groups and in children with special needs such as children with cerebral palsy and Down syndrome. The study has high clinical implication that MCPS could be estimated by knowing only the age of the primary schoolchildren with the help of prediction equation. This greatly reduces the time in estimating RT/ MCPS through any known objective method.

\section{Conclusion}

MCPS of the primary schoolchildren can be estimated by prediction equation through RDM. This might act as a key for many doors in cognitive psychology.

\section{Declaration of patient consent}

The authors certify that they have obtained all appropriate patient consent forms. In the form the patient(s) has/have given his/her/their consent for his/her/their images and other clinical information to be reported in the journal. The patients understand that their names and initials will not be published and due efforts will be made to conceal their identity, but anonymity cannot be guaranteed.

\section{Acknowledgments}

The authors are very thankful to Mr. Valerian Clement Aranha, Mrs. Philomena Aranha, Ms. Vevita Priya Aranha and Mr. Valesh Prajwal Aranha, Karkala, Karnataka, India, for their immense contribution to the successful completion of this study.

\section{Financial support and sponsorship \\ Nil.}

\section{Conflicts of interest}

There are no conflicts of interest.

\section{References}

1. Ilamkar KR. Analysis of human information processing in performance and cognition. Int J Res Health Sci 2014;2:36-40.

2. Grane VA, Endestad T, Pinto AF, Solbakk AK. Attentional control and subjective executive function in treatment-naive adults with Attention Deficit Hyperactivity Disorder. PLoS One 2014;9:e115227.
3. Silva AP, Prado SO, Scardovelli TA, Boschi SR, Campos LC, Frère AF. Measurement of the effect of physical exercise on the concentration of individuals with ADHD. PLoS One 2015;10:e0122119.

4. Sayeur MS, Vannasing P, Tremblay E, Lepore F, McKerral M, Lassonde M, et al. Visual development and neuropsychological profile in preterm children from 6 months to school age. J Child Neurol 2015;30:1159-73.

5. Literature Review on Reaction Time. Available from: http://www.fon hum.uva.nl/rob/Courses/InformationInSpeech/CDROM/Literature/ LOTwinterschool2006/biae.clemson.edu/bpc/bp/Lab/110/reaction. htm. [Last cited on 2016 Mar 26].

6. Bolfer C, Casella EB, Baldo MV, Mota AM, Tsunemi MH, Pacheco SP, et al. Reaction time assessment in children with ADHD. Arq Neuropsiquiatr 2010;68:282-6.

7. Ruler Drop Test. Available from: http://www.brianmac.co.uk/rulerdrop. htm. [Last cited on 2016 Mar 26].

8. Eckner JT, Whitacre RD, Kirsch NL, Richardson JK. Evaluating a clinical measure of reaction time: An observational study. Percept Mot Skills 2009;108:717-20.

9. Aranha VP, Joshi R, Samuel AJ. Estimating Reaction Time in the Children with Typical Development - A Pilot Study. Ghaziabad, India: Paper Presented at: Physiocon 2014-National Physiotherapy Conference; 2014.

10. Unsworth CA. Cognitive and perceptual dysfunction. In: Sullivan SB, Schmitz TJ, Fulk GD, editors. Physical Rehabilitation. $6^{\text {th }}$ ed. Philadelphia: FA Davis Company; 2014. p. 1222.

11. Aranha VP, Joshi R, Samuel AJ, Sharma K. Catch the moving ruler and estimate reaction time in children. Indian J Med Health Sci 2015;2:23-6.

12. F00-Notes. 11b. Available from: http://www.pas.rochester.edu/ stte/ phy104-F00/n11/notes-11b.html. [Last cited on 2016 Mar 11].

13. The Galileo Project | Science | On Motion. Available from: http://www. galileo.rice.edu/sci/theories/on_motion.html. [Last cited on 2016 Mar 11].

14. The Motion of Falling Bodies. Available from: http://www.physics. ucr.edu/ wudka/Physics $7 /$ Notes_www/node49.html. [Last cited on 2016 Mar 11].

15. Baayen RH, Milin P. Analyzing reaction times. Int J Psychol Res 2015;3:12-28.

16. Fong SS, Ng SS, Chung LM. Health through martial arts training: Physical fitness and reaction time in adolescent Taekwondo practitioners. Health 2013;5:1-5. Available from: http://www.scirp.org/ journal/ PaperDownload.aspx?DOI=10.4236/health. 2013.56A3001. [Last cited on 2016 Mar 26].

17. Brown HM, Eley TC, Broeren S, Macleod C, Rinck M, Hadwin JA, et al. Psychometric properties of reaction time based experimental paradigms measuring anxiety-related information-processing biases in children. J Anxiety Disord 2014;28:97-107.

18. Gavkare AM, Nanaware NL, Waghmare AR, Taware GB, Surdi AD. Study of flexibility, agility and reaction time in circus artists. Int J Recent Trends Sci Technol 2011;1:49-55. Available from: http://www. journals.indexcopernicus.com/abstract.php?icid $=978088$. [Last cited on 2016 Mar 26].

19. Saxena C, Kaur R, Arun P. Reaction time of a group of physics students. Phys Educ 2008;21:309-13.

20. Kiselev S, Espy KA, Sheffield T. Age-related differences in reaction time task performance in young children. J Exp Child Psychol 2009;102:150-66.

21. Batra A, Vyas S, Gupta J, Gupta K, Hada R. A comparative study between young and elderly Indian males on audio-visual reaction time. Indian J Sci Res Technol 2014;2:25-9.

22. DeGoede KM, Ashton-Miller JA, Liao JM, Alexander NB. How quickly can healthy adults move their hands to intercept an approaching object? Age and gender effects. J Gerontol A Biol Sci Med Sci 2001;56:M584-8.

23. Casey BJ, Tottenham N, Liston C, Durston S. Imaging the developing brain: What have we learned about cognitive development? Trends Cogn Sci 2005;9:104-10.

24. Rueda MR, Fan J, McCandliss BD, Halparin JD, Gruber DB, Lercari LP, et al. Development of attentional networks in childhood. Neuropsychologia 2004;42:1029-40. 